springs and plates became easier to move. It was, as the speaker said, as if the guy ropes supporting the teeth had been slackened off. $\mathrm{He}$ doubted if it would be common practice for a dentist to prescribe a hormone, using the side-effect as the reason for exhibiting the drug.

It does, however, raise another interesting question and we could surely sympathize with the conscience of the lady who might explain that she was given the pill by her dentist to straighten her teeth.-I am, etc.,

Manchester 21.

\section{N. BARBER.}

REFERENCES

1 Barber, D. N., Brit. med. F., 1967, 4, 417. 2 Lindhe, J., and Björn, A. L., f. Periodont. Res.,

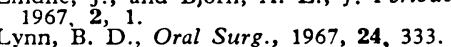

- Manchester Dental Study Forum 13-15 September 1968

\section{Oral Contraceptives and Thromboembolic Disease}

SiR,-In both papers, one by Drs. W. H. W. Inman and M. P. Vessey (27 April, p. 193) and a second by Drs. M. P. Vessey and Richard Doll (p. 199), on the relationship of oral contraceptives to thromboembolic disease careful attention is paid to a number of factors that might have introduced bias into the studies. However, no mention is made regarding the basic design of the studies which appears to bias the selection of cases for analysis against the contraceptive users.

In the first study, of 499 cases reviewed from death certificate data, 190 were excluded for a variety of reasons. Among those excluded from consideration were 94 cases, the majority of which, presumably, would be women who were not "pill takers" (49 spinsters, 18 widowed, divorced, or separated, and 27 not registered with a physiciansince the "pill" is a prescription drug, such women would not likely be on it). If these 94 cases were included in the study and a matched number of controls also included (which would not alter this group significantly), the number of fatalities from thromboembolism in contraceptive users would be significantly altered to approximately $13 \%$ instead of the given figure of $17 \%$ of the cases. The simple fact that the remaining $87 \%$ of the deaths so analysed occurred in non-users also bears emphasis.

Another curious fact brought out in this study, one which is quite difficult to understand, is that in the group of women dying of thromboembolism those contraceptive users who were deemed to have "predisposing conditions" did not show a significant difference in the incidence of pulmonary embolism from the non-users. Yet those women who were deemed to be healthy, that is without "predisposing causes," were found to have a striking predilection to thromboembolic disease when they took contraceptive pills. Of further interest is that in this same healthy group, the expected incidence of deaths in contraceptive users was only one-fourth of the actual incidence, while the expected incidence of deaths among the non-users was twice that of the observed number. Thus, I am puzzled why there seems to be an increased incidence of pulmonary embolism in "healthy pill takers" while there is no increase in those who already have conditions predisposing to thromboembolic disease. Likewise, I find it difficult to arrive at an explanation for the difference in expected incidence of deaths from the observed incidence in the control group.
In the second paper, which consisted of a review of records of 399 women admitted to hospitals with venous thrombosis or pulmonary embolism, only 58 were considered acceptable for analysis. Most important in this "selection" again, is that of those excluded for a variety of reasons 43 were excluded because they were spinsters or widowed. Had this group been included (with an equal number of controls in the same category), the final figures would likely have been quite different. Presuming this group to be comprised primarily of nonusers, instead of 26 of 58 contraceptive users having thromboembolic disease, we find the figures would correct to 30 of 101 ; and for the controls, instead of 10 of 116 , they would correct to 18 of 202. Thus, the incidence of thromboembolic disease in those using oral contraceptives would be approximately three times that of nonusers rather than the reported incidence of 12 times.

One might consider the liberties I have taken with these data to be unjust, but none the less these "adjustments" serve to point out what appears to be a significant fault in the design of these studies upon which the authors did not comment, Thus it would seem, when one designs a study based on total mortality statistics or total hospital admissions for a specific disease occurring in all women, and then compares only married women, even though the controls are also married, he introduces an unfair bias into the study which may materially alter the results. Only by a completely controlled prospective study can the information on thromboembolic disease and contraceptive use sought by these studies be precisely defined.

It seems unfortunate that this work has received such wide recognition as having answered this critical question. It is indeed, however, refreshing to know that, despite the "evidence" set forth by the authors, that it is apparently still safer to take the pill than to drive your car or to crawl into bed without taking your pill.-I am, etc.,

$$
\text { John J. Deller, Jun. }
$$

\section{Department of Medicine,

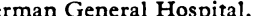 \\ San Francisco, California, U.S.A.}

\section{Iliacus Haematoma and Nerve Palsy}

SIR,-I was interested in a report by Mr. C. B. d'A. Fearn (12 October, p. 97) of the iliacus haematoma syndrome complicating anticoagulant treatment. Although, as was stated in the discussion, it is more frequently a complication of haemophilia and Christmas disease, an iliacus haematoma from direct trauma in an otherwise normal individual can be associated with the femoral nerve palsy.

An instance of this was recently encountered in a boy of 16, who was admitted to the Radcliffe Infirmary after a fall on to his left hip from his motor-cycle. There was bruising around the iliac crest anteriorly and over the greater trochanter. An $x$-ray of his pelvis revealed a comminuted fracture of the anterosuperior iliac spine. The following day he complained of numbness over the front of his left thigh, and was found to have loss of sensation to light touch and pinprick over the femoral nerve distribution and marked weakness of his quadriceps with loss of knee extension against gravity. There was a large swelling on the medial aspect of the ilium, but no definite evidence of a psoas swelling. Within 48 hours both sensory disturbance and quadriceps power had recovered completely.
The site of the trauma above the inguinal ligament would tend to support the hypothesis of Goodfellow et al. ${ }^{1}$ that nerve compression in this syndrome results in distension of the ilio-psoas compartment.-I am, etc.,

$$
\begin{aligned}
& \text { Accident Service, } \\
& \text { Raddliffe Infirmary, T. R. FISHER. } \\
& \text { Oxford. } \quad \text { REFERENCE } \\
& \text { Goodfellow, J., Fern, C. B. d'A., and Mathews, } \\
& \text { J. M., J. Bone ft Surg., 1967, 49B, 748. }
\end{aligned}
$$

\section{Drinking Drivers}

SIR,-Many thousand drivers have failed the road-side "breathalyser" test. This surprises few of us with experience in this field. However, many hundred drivers who fail the second breath test are subsequently found to have a blood alcohol level of less than $80 \mathrm{mg} . / 100 \mathrm{ml}$.

It seems time now for the British Medical Association to recommend to the police that such drivers be given the opportunity of washing their mouths and dentures with water before a second breathalyser test is demanded. This seems an inexpensive way of avoiding trouble.-I am, etc.,

$$
\begin{aligned}
& \text { JAMES HERD HENDERSON, } \\
& \text { Surgeon to “A " Division, } \\
& \text { Renfrew and Bute Constabulary. } \\
& \text { Greenock, Renfrewshire. }
\end{aligned}
$$

\section{Withdrawal of Drugs}

SiR,-Mr. R. F. Heys (14 September, p. 682 ) is justifiably concerned about the sudden withdrawal of drugs from the market without prior notice.

Some time ago the anaesthetists of Great Britain found themselves unable to obtain what was virtually the only anaesthetic suitable for spinal anaesthesia (heavy Nupercaine ; cinchocaine). Those of us who think subarachnoid block has still an important part to play in modern anaesthetic technique are rapidly nearing the end of our stocks of this drug, and are anxiously awaiting the outcome of the Dunlop Committee's recommendations on the matter. Refusal by them to authorize the distribution of an alternative drug suitable for subarachnoid anaesthesia would virtually prohibit the use of this technique in Great Britain.-I am, etc.,

J. F. Rickards. South Staffordshire Medical Centre,

\section{Medical Teachers' Training College}

SIR,-Medical teaching is today one of the few disciplines in which the teacher is not taught how to teach. However, in the vast field of education a potential teacher has to go to a teacher training college, where he can learn methods of teaching for both children and adults. Here, too, he learns how to give a lecture or conduct a tutorial. The subject matters little, provided the teacher has learnt to project it.

Even more important than a lecture or tutorial is a method of teaching, perhaps difficult to master, but probably more effective in results. I refer, of course, to the method of repetition where the student learns a set portion before the actual lecture and 